\title{
Post-operative unadjuvanted therapeutic xenovaccination with chicken whole embryo vaccine suppresses distant micrometastases and prolongs survival in a murine Lewis lung carcinoma model
}

\author{
JAN ALEKSANDER KRAŚKO ${ }^{1-3}$, KAROLINA ŽILIONYTE் $^{1}$, ADAS DARINSKAS $^{1,3,4}$, \\ NERINGA DOBROVOLSKIENE ${ }^{1}$, AGATA MLYNSKA ${ }^{1}$, SVETLANA RIABCEVA $^{5}$, \\ IOSIF ZALUTSKY ${ }^{5}$, MARINA DEREVYANKO ${ }^{5}$, VLADIMIR KULCHITSKY ${ }^{5}$, \\ OLGA KARAMAN $^{6}$, NATALIA FEDOSOVA ${ }^{6}$, TATIANA VASYLIYVNA SYMCHYCH ${ }^{6}$, \\ GENNADY DIDENKO $^{6}$, VASYL CHEKHUN ${ }^{6}$, MARIUS STRIOGA $^{1}$ and VITA PAŠUKONIENE ${ }^{1}$ \\ ${ }^{1}$ Laboratory of Immunology, National Cancer Institute, Vilnius, Vilnius LT-08660; ${ }^{2}$ Department of Immunology, \\ State Research Institute Centre for Innovative Medicine, Vilnius, Vilnius LT-08406; ${ }^{3}$ Department of Manufacturing, \\ JSC 'Froceth', Vilnius, Vilnius LT-08217; ${ }^{4}$ JSC ‘Innovita Research', Vilnius, Vilnius LT-06118, Lithuania; \\ ${ }^{5}$ Departments of Neurophysiology and Pathology, Institute of Physiology, Minsk, Minsk BY-220072, Republic of Belarus; \\ ${ }^{6}$ Laboratory of Oncoimmunology and Antitumour Vaccine Engineering, R.E. Kavetsky Institute of Experimental Pathology, \\ Oncology and Radiobiology, NAS of Ukraine, Kyiv, Kyivs'ka 03022, Ukraine
}

Received May 26, 2017; Accepted November 20, 2017

DOI: $10.3892 / 01.2018 .7950$

\begin{abstract}
Immunotherapy in the form of anticancer vaccination relies on the mobilization of the patient's immune system against specific cancer antigens. Instead of focusing on an autologous cell lysate, which is not always available in clinical practice, the present study investigates vaccines utilizing xenogeneic foetal tissue that are rich in oncofoetal antigens. Lewis lung carcinoma (LLC)-challenged C57BL/6 mice were treated with either a xenogeneic vaccine made from chicken whole embryo, or a xenogeneic vaccine made from rat embryonic brain tissue, supplemented with a Bacillus subtilis protein fraction as an adjuvant. Median and overall survival, size of metastatic foci in lung tissue and levels of circulating $\mathrm{CD} 8 \mathrm{a}^{+} \mathrm{T}$ cells were evaluated and compared with untreated control mice. Following primary tumour removal, a course of three subcutaneous vaccinations with xenogeneic chicken embryo vaccine led to significant increase in overall survival rate (100\% after 70 days of follow-up vs. $40 \%$ in untreated control mice), significant increase in circulating $\mathrm{CD} 8 \mathrm{a}^{+} \mathrm{T}$ cells (18.18 vs. $12.6 \%$ in untreated control mice), and a significant decrease in the area and incidence of metastasis foci. The xenogeneic rat brain tissue-based vaccine did not improve
\end{abstract}

Correspondence to: Dr Jan Aleksander Kraśko, Laboratory of Immunology, National Cancer Institute, Santariškių 1, Vilnius, Vilnius LT-08660, Lithuania

E-mail: krasko.jan@gmail.com

Key words: xenogeneic, vaccination, Lewis lung carcinoma, mice, metastasis, cytotoxic lymphocytes any of the investigated parameters, despite promising reports in other models. We hypothesize that the proper selection of antigen source (tissue) can constitute an effective immunotherapeutic product.

\section{Introduction}

Through the immunosurveillance process, the immune system is the main line of defence against cancer (1). Nevertheless, $\sim 14$ million cancer cases are diagnosed worldwide annually (2), indicating that, under certain circumstances, malignant cells can break the protective barrier of spontaneous antitumour immunity and develop into clinically detectable cancer. Malignant cells exploit various immune escape mechanisms, creating a microenvironment favourable for cancer growth and metastasis (3). Therefore, substantial effort has been initiated to manipulate antitumour immune responses by therapeutic interventions, known as cancer immunotherapy. Of the various types of cancer immunotherapy (4), therapeutic cancer vaccinations are one of the most extensively studied, with the first clinical trial in melanoma patients dating back to 1998 (5). Therapeutic cancer vaccinations exploit dendritic cells in situ and their unique capacity to induce and orchestrate antigen-specific immune responses (6). These vaccinations aim to reprogram imbalanced antitumour immunity by inducing or re-stimulating robust tumour-associated antigen (TAA)-specific cytotoxic immune responses (7).

The inherent tolerogenicity/low immunogenicity of TAAs is an obstacle to effective spontaneous and vaccination-induced antitumour immunity. Since all TAAs (apart from oncoviral TAAs) are derived from self-proteins, TAAs possess a certain degree of tolerance, depending on their type $(4,8)$. Changes in the structure and/or expression pattern of TAAs should 
be sensed as a danger by the immune system and invoke its reactivity. However, TAAs with minor alterations can resemble self-proteins and sneak through the 'detectors' of the immune system (8). Therefore, a concept of xenogeneic immunization, using homologous antigens derived from different species (xenoantigens), was proposed to overcome immune tolerance to such sham TAAs (9-12). A number of genes are evolutionarily conserved between different animal species $(13,14)$. However, interspecies sequence variations also exist $(9,15,16)$. Therefore, homologous xenoantigens differ sufficiently from self-antigens to render them immunogenic, but preserve an optimal homology range with self-proteins enabling them to induce $\mathrm{T}$ cell cross-reactivity with self TAAs $(9,16,17)$. Moreover, xenoepitopes can bind host major histocompatibility complex (MHC) molecules even more strongly compared with native homologous epitopes (15). Sustained xenogeneic peptide/MHC complexes induce more robust xenoantigen-specific T-cell responses that are cross-reactive with self TAAs.

Of the various TAAs, oncofoetal (18) and cancer-testis (CT) (19) antigens are of great interest in the context of tumour immunotherapy. These antigens are products of 'silent' genes whose expression is normally repressed in postnatal organisms with the exception of the immune-privileged organs, including the testes and placenta. The expression of these antigens can be aberrantly reactivated in cancer cells (19). CT antigens possess a high immunogenic potential since they are 'unknown' to the adult immune system (19). Oncofoetal antigens are usually not expressed in adult organisms, or are expressed in a limited quantity in specific organs. However, oncofoetal antigens can be expressed in cancer cells (20). Notably, antibodies against CT antigens were detected in patients with gastric and lung cancer, and were associated with prolonged survival time (21). Similarly, tumour-bearing mice expressed antibodies against chicken embryo protein (CEP)-containing vaccine even prior to the administration of the vaccine, indicating that the CEP vaccine (hereafter referred to as 'xeno chicken') contains antigens that were in common with various types of cancer, including Lewis lung carcinoma (LLC), Ehrlich carcinoma and Sarcoma 37 (22). This data supports the credibility of using prenatal tissues as a source of antigens in therapeutic cancer vaccines, with the aim of exploiting their strong intrinsic immunogenicity and potential in facilitating immune recognition. The availability of xenogeneic foetal tissue would make it an affordable form of treatment among others, which are very expensive immunotherapies. This potential is already being investigated in recent trials involving xenogeneic vaccines $(23,24)$, where patients with stage III melanoma were treated with xenogeneic polyvalent vaccine, based on murine B16 and LLC tumours. The 5-year survival rate for patients treated with the vaccine was significantly better compared with the controls (55 vs. 18\%).

The present study investigated the immunological and therapeutic (micrometastases-suppressing) efficacy of postoperative xenovaccination in a murine LLC model. In spite of the reports raising the question whether LLC and 3LL cell lines are actually the same cell line, all sources cited in the present study were using the LLC-labelled cell line for the LLC model, therefore this variant was used to maintain consistency across the studies. Two xenogeneic vaccines were investigated, a patented rat embryonic nervous tissue-based xenovaccine adjuvanated with a protein-containing metabolite of Bacillus subtilis B-7025 (25) and unadjuvanted whole chicken embryo xenogeneic vaccine (22).

\section{Materials and methods}

Mice and cell lines. A total of 30 C57BL/6 mice (8-12 weeks old; female) were obtained from the State Research Institute Centre for Innovative Medicine (Vilnius, Lithuania). The mice were housed in plastic cages ( $\leq 15$ mice per cage) under normal daylight conditions with ad libitum access to water and food. All animal procedures were performed in accordance with the directive of the European Parliament and of the Council on the protection of animals used for scientific purposes (26) alongside the approval of Lithuania State Food and Veterinary Service. The mice were sacrificed by cervical dislocation.

The murine metastatic Lewis lung carcinoma LLC1 cell line was a gift from the RE Kavetsky Institute of Experimental Pathology, Oncology and Radiobiology (Kiev, Ukraine). The cells were cultivated in Dulbecco's modified Eagle's medium (Lonza Group, Ltd., Basel, Switzerland) containing $2 \mathrm{mM}$ L-glutamine, $10 \%$ foetal bovine serum (Gibco; Thermo Fisher Scientific, Inc., Waltham, MA, USA), $100 \mathrm{U} / \mathrm{ml}$ penicillin and $100 \mu \mathrm{g} / \mathrm{ml}$ streptomycin (Gibco; Thermo Fisher Scientific, Inc.) in a humidified atmosphere containing $5 \% \mathrm{CO}_{2}$ at $37^{\circ} \mathrm{C}$.

Vaccine preparation. The rat embryo nervous tissue vaccine ('xeno rat' vaccine) used in the present study has been patented by the Ukrainian Intellectual Property Institute (27). The vaccine contains a protein fraction of nervous tissue from late gestation stage rat embryo (a source of TAAs) and an adjuvant, which is a protein-containing metabolite of B. subtilis B-7025 (molecular weight, $70 \mathrm{kDa}$ ) (27). The whole chicken embryo vaccine was prepared as follows: 7-day-old chicken embryos were rinsed twice briefly in cold $0.9 \% \mathrm{NaCl}$ solution, homogenized and then extracted with $0.9 \% \mathrm{NaCl}$ solution containing $0.1 \%$ EDTA for $60 \mathrm{~min}$ at $4^{\circ} \mathrm{C}$ by agitation. Following extraction, chicken embryo tissue was removed by centrifugation at $1,500 \mathrm{x}$ g for $30 \mathrm{~min}$ at $4^{\circ} \mathrm{C}$. The resulting supernatant containing chicken embryo protein was collected and frozen at $-20^{\circ} \mathrm{C}$ (the 'xeno chicken' vaccine) $(28,29)$. The two vaccines were developed at the R. E. Kavetsky Institute of Experimental Pathology, Oncology and Radiobiology (Kyiv, Ukraine).

Postoperative (adjuvant) therapeutic xenovaccination in the LLC model. On day 0, $30 \mathrm{C} 57 \mathrm{BL} / 6$ mice received a subcutaneous injection of $3 \times 10^{5}$ LLC cells in the left hind foot. The foot was chosen as the site of tumour inoculation owing to the ease of resection, which contributed to the $100 \%$ surgical survival rate in the present study. The hind foot was specifically chosen as mice recover better with their front legs intact. Although the tumours were located in the foot, no bleeding or self-harm was noted at the tumour site. On day 14 following injection, primary tumours were surgically removed by amputating the foot under general anaesthesia, using intraperitoneal ketamine (100 mg/kg)-xylazine (10 mg/kg) injections. The mice were allowed to recover under a heat lamp and were monitored for $2 \mathrm{~h}$ or until they were able to uphold an upright position, at which point they were returned to standard cages. The mice with the primary 


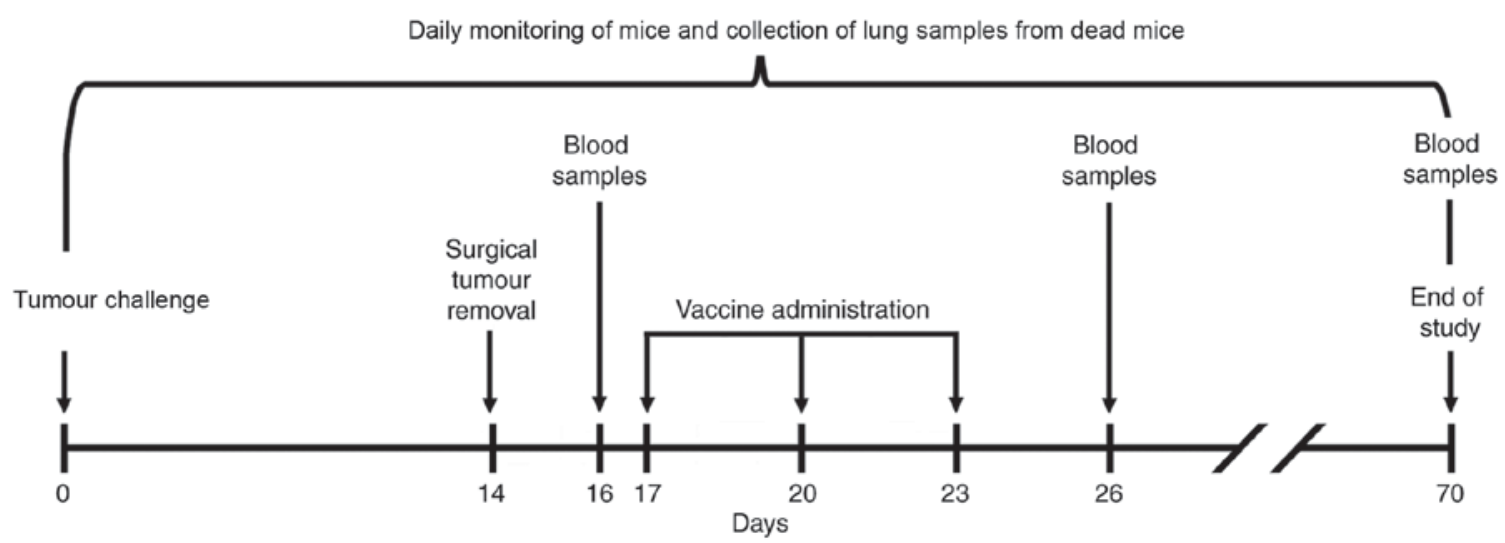

Figure 1. Experimental anticancer vaccination and sampling scheme for C57BL/6 mice challenged with LLC cells. Experiment design depicted from the time of tumor challenge (day 0) to the end of the survival observation (day 70). Figure presented previously (39).

tumour removed were subsequently treated with either the xeno rat vaccine $(n=10)$ or the xeno chicken vaccine $(n=10)$. The mice that underwent surgical LLC removal and were receiving saline injections $(n=10)$ served as the control group. The mice in each group were vaccinated as follows: Each vaccine was injected subcutaneously into the nape of the neck on days 17, 20 and 23. Internal organs were analysed for detection and characterization of LLC metastases in animals that has succumbed to disease. Blood samples were collected at various time points for analysis of cluster of differentiation $8^{+}\left(\mathrm{CD}^{+}\right)$T-lymphocyte population. The experimental design is depicted in Fig. 1.

Sampling. To assess the anticancer effects of the vaccines, mice lung and blood samples were obtained (Fig. 1). The lungs were analysed histologically for metastasis, as this is the preferred metastatic location for the LLC cell line (30). Other internal organs (liver, kidney, pancreas and brain) were visually analysed for metastases. Blood samples were collected from the hip vein prior to the onset of vaccination (on day 16), 3 days after the completion of therapeutic vaccination (on day 26) and at the end of the experiment (on day 70) from the surviving mice of each experimental group. The mice that were found to have succumbed or sacrificed owing to critical condition during the follow-up period underwent histological analysis, as did mice sacrificed at the end of the experiment.

The survival of mice was observed daily throughout the experiment. Owing to the primary tumour resection, tumour growth could not be used to establish a humane endpoint of the study. Therefore, a time limit of 70 days was introduced. The humane endpoint for individual mice was set subjectively by the technical staff, which were blinded to the purpose of the experiment, and euthanized the animal when they appeared to be in a critical condition. This procedure could only be applied within working hours (07:00-17:00) and at two time points during the weekends (mornings and evenings). Owing to these time constraints, one control mouse was not euthanized, but found to have succumbed at the beginning of the working day, which was fixed as the date of mortality. This event contributed to $8 \%$ of the total of mice that succumbed to disease by the end of the experiment.
Histological analysis of LLC metastases. For histological analysis, lung tissue was fixed in $10 \%$ neutral buffered formalin for $24 \mathrm{~h}$ at room temperature, dehydrated in alcohol baths at room temperature $(70 \%$ for $12 \mathrm{~h}$; $90 \%$ for $12 \mathrm{~h}$; $100 \%$ for $24 \mathrm{~h}$ ) and embedded in paraffin. The paraffinized samples were serially cut into sections (thickness, $3 \mu \mathrm{m}$ ) using a microtome. The sections were deparaffinized, rehydrated and stained with haematoxylin (15 min) and eosin (5 sec) at room temperature. Each section was examined under a light microscope to identify the tumour-infiltrated areas. The images were captured using an automated Leica DM50000 B microscope equipped with a Leica DFC420 C digital camera (Leica Microsystems, GmbH, Wetzlar, Germany). Images were processed and analysed using the ImageJ image analysis program (version $1.48 \mathrm{k}$; National Institutes of Health, Bethesda, MD, USA), as described previously (31). The area of all tumour nodules that were found in lung tissue was estimated using the 'Freehand selection tool' in ImageJ and measurements were expressed in $\mathrm{mm}^{2}$.

Flow cytometry. For analysis of $\mathrm{CD}^{+} \mathrm{a}^{+} \mathrm{T}$ cell population, $100 \mu \mathrm{l}$ blood were collected from the hip vein from each mouse. Whole blood was stained with anti-CD8-phycoerythrin (PE) (cat no. 552877; BD Biosciences, Franklin Lakes, NJ, USA) and anti-CD3-allophycocyanin (APC) (cat no. 553066, BD Biosciences) antibodies (1 $\mu 1 / 100 \mu 1$ blood, $25 \mathrm{~min}$ incubation at room temperature). Erythrocytes were lysed using ACK Lysing buffer (Gibco; Thermo Fisher Scientific, Inc.). For FACS, 20,000 events were collected using BD FACSDiva ${ }^{\mathrm{TM}} 7.0$ flow cytometer (BD Biosciences) and analyzed with FlowJo ${ }^{\mathrm{TM}}$ (version 10.2; FlowJo LLC, USA) software.

Statistical analysis. $\mathrm{P} \leq 0.05$ was considered to indicate a statistically significant difference. For statistical analysis Statistica 12 (Tibco Software, Inc., La Jolla, CA, USA) software was used. Non-parametric Kruskal-Wallis was used for statistical survival data analysis of the animals surviving at the end of the experiment. Once this test was performed, Kaplan-Meier analysis followed by long-rank analysis was used for group analysis as it is the most widely used test for survival analysis (32). As it was shown that for smaller samples 
( $<50$ per group) it is worth using a more powerful statistical test (33), Cox's F-test (34) was also used, as groups in this study were smaller than 50 specimens. Flow cytometry data was analysed using an unpaired, two-tailed Student's t-test (35). The differences between tumour areas in lung histological slides were assessed using the Mann-Whitney U-test (36).

\section{Results}

Survival of mice treated with postoperative therapeutic xenovaccination in the LLC-metastatic model. A total of $30 \mathrm{C} 57 \mathrm{BL} / 6$ female mice were subcutaneously injected with $3 \times 10^{5}$ LLC cells in the left hind-foot, and all of the mice developed visually detectable tumours at the injection site. On day 14, the foot with the primary tumour was surgically resected. No surgery-associated causalities were recorded. The mice were subsequently treated with either the xeno rat vaccine $(n=10)$ or the xeno chicken vaccine $(n=10)$ or injected with saline solution $(n=10)$.

Mice treated with the xeno chicken vaccine maintained a $100 \%$ survival rate over the observation period of 70 days. The xeno chicken vaccine-treated mice survived significantly longer compared with the mice treated with the xeno rat-vaccine and control group animals [Kruskal-Wallis analysis, $\mathrm{H}(2, \mathrm{n}=31)=9.644 ; \mathrm{P}=0.008$; Fig. 2].

Xenovaccination-associated changes in circulating $C D 8 a^{+}$ cytotoxic T-cell population. In each experimental group, blood samples were collected from the hip vein at three time points: i) On day 16 (i.e., two days after tumour removal and one day prior to the start of therapeutic xenovaccination); ii) on day 26 (two days after completion of therapeutic xenovaccination), and iii) on day 70 (at the end of the experiment for the surviving mice).

As shown in Fig. 3, a significant increase in circulating $\mathrm{CD} \mathrm{a}^{+} \mathrm{T}$-cell level was observed at the end of the observation period (day 70) only in mice treated with the xeno chicken vaccine.

As indicated in Fig. 4, the results from the control (Fig. 4A), xeno rat (Fig. 4B) and xeno chicken (Fig. 4C) treatment groups are presented as histograms. Notably, a strong positive correlation $(r=0.985, \alpha=0.05)$ was established between mean overall survival (mOS) and circulating CD8 $\mathrm{a}^{+} \mathrm{T}-$ cell level.

Effect of xenogeneic vaccines on metastatic spread into the lungs. All mice that succumbed to disease in any experimental arm during the observation period had metastatic infiltrates in the lungs. Additionally, all control mice had metastatic foci in the liver. On day 70 (at the end of the observation/experiment), metastatic foci in the lungs were detected in 3 out of 10 of the surviving mice that were treated with the xeno chicken vaccine and in 1 out of 4 of the surviving mice that were treated with the xeno rat vaccine. All surviving mice in the control group $(n=4)$ had metastatic infiltrates in lung tissue (see Fig. 5 for representative images of metastatic infiltration). Notably, the analysis of lung metastases from animals with metastatic spread revealed that the mean area of metastatic foci in the xeno chicken vaccination group was significantly smaller compared with mice that were treated with xeno rat vaccine $\left(0.04 \pm 0.001 \mathrm{~mm}^{2}\right.$ vs. $1.812 \pm 0.647 \mathrm{~mm}^{2}$, respectively; $\mathrm{P}=0.034$ ) or the control

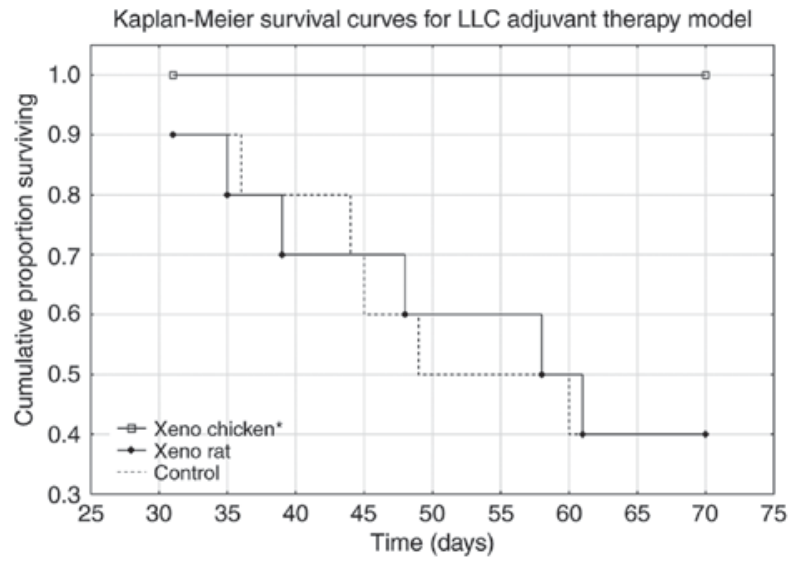

Figure 2. Kaplan-Meier survival curves for mice receiving adjuvant treatment with different xenogeneic vaccines following the removal of primary LLC-derived tumors. The mice that were treated with the xeno chicken vaccine survived significantly longer (mOS, 70 days) compared with the mice that were treated with the xeno rat vaccine $(\mathrm{mOS}, 60$ days; $\mathrm{P}=0.003)$ and control group animals (mOS, 55 days; $\mathrm{P}=0.003$ ). There was no significant difference in survival between the xeno rat and control groups. For each treatment arm, $\mathrm{n}=10$. LLC, Lewis lung carcinoma; mOS, mean overall survival.

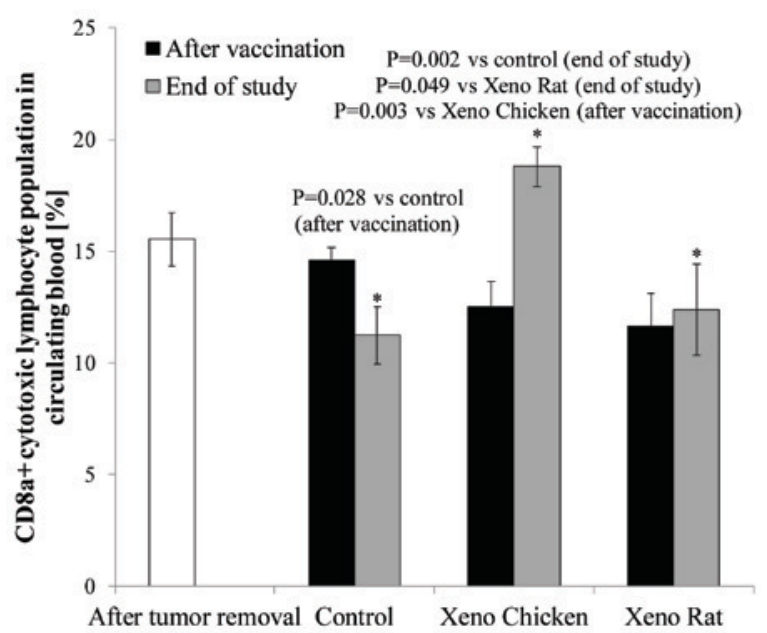

Figure 3. Percentage of $\mathrm{CD}^{+} \mathrm{a}^{+} \mathrm{T}$ cells in circulating peripheral blood monocytes prior to therapeutic xenovaccination (day 16, white column), 3 days after the completion of xenovaccination (day 26, black columns) and at the end of the study (day 70, grey columns). There were no significant changes in the levels of circulating CD8 $\mathrm{a}^{+} \mathrm{T}$ cells 3 days after the completion of xenovaccination, compared with the levels prior to the start of vaccination (within and between the experimental arms). However, on day 70 (at the end of the observation period), the levels of circulating CD8 $\mathrm{a}^{+} \mathrm{T}$ cells were significantly higher in the surviving mice vaccinated with the xeno chicken vaccine $(n=10)$ compared with surviving mice $(\mathrm{n}=4)$ in the control group $(\mathrm{P}=0.002)$ or in the Xeno Rat group $(\mathrm{P}=0.049)$. In xeno chicken vaccine-treated mice, the level of $\mathrm{CD} 8 \mathrm{a}^{+} \mathrm{T}$ cells on day 70 was significantly higher compared with the level on day 16 (following tumor removal, prior to xenovaccination) $(\mathrm{P}=0.036)$ and on day 26 ( 3 days after the completion of xenovaccination) $(\mathrm{P}=0.003)$. There were no significant differences in the levels of circulating $\mathrm{CD} \mathrm{a}^{+} \mathrm{T}$ cells in the mice that were treated with xeno rat vaccines evaluated at different time points or comparing T-cell levels with those in control group animals. Additionally, there was a significantly lower CD8 $\mathrm{a}^{+} \mathrm{T}$-cell population in the control mice at the end of the study (day 70) compared with the level following the completion of vaccination (day 16) $(\mathrm{P}=0.028)$. CD8a, cluster of differentiation $8 \mathrm{a}$. ${ }^{*} \mathrm{P} \leq 0.05$.

mice $\left(1.62 \pm 0.2 .2 \mathrm{~mm}^{2} ; \mathrm{P}=0.027\right)$. However, metastatic foci in mice that were treated with xeno rat vaccine did not differ significantly from the foci detected in control mice $(\mathrm{P}=0.753)$. 
A

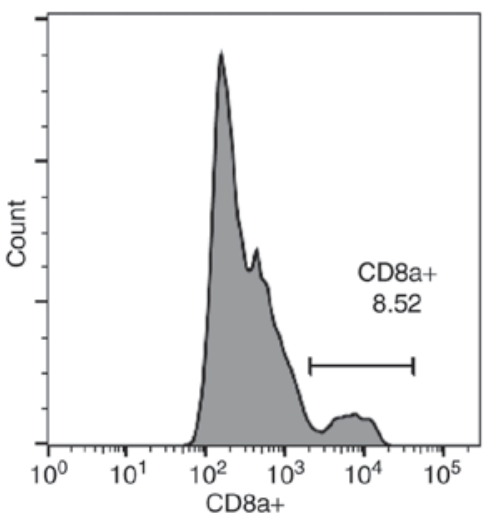

B

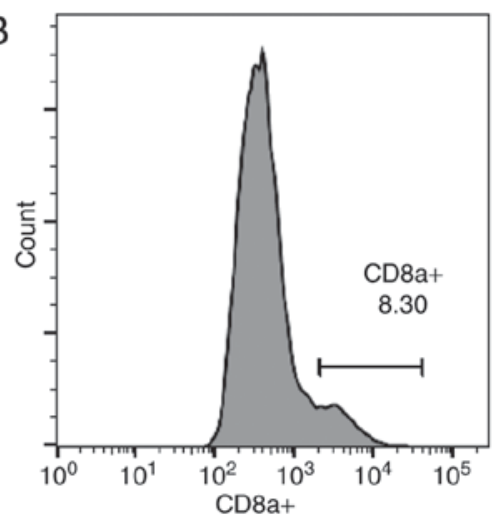

C

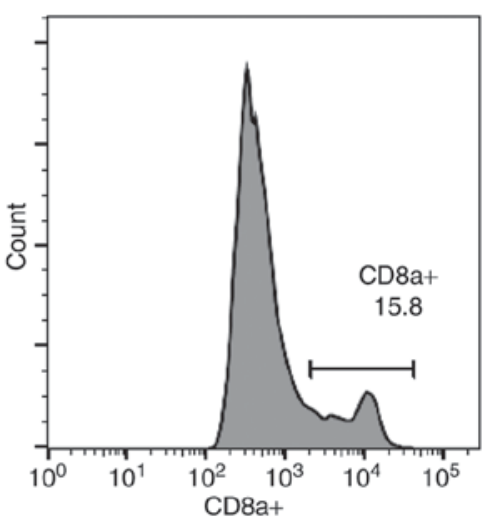

Figure 4. CD8 $\mathrm{a}^{+}$flow cytometric analysis. Histograms for the (A) control, (B) xeno rat and (C) xeno chicken treatment groups. CD8a, cluster of differentiation 8a.

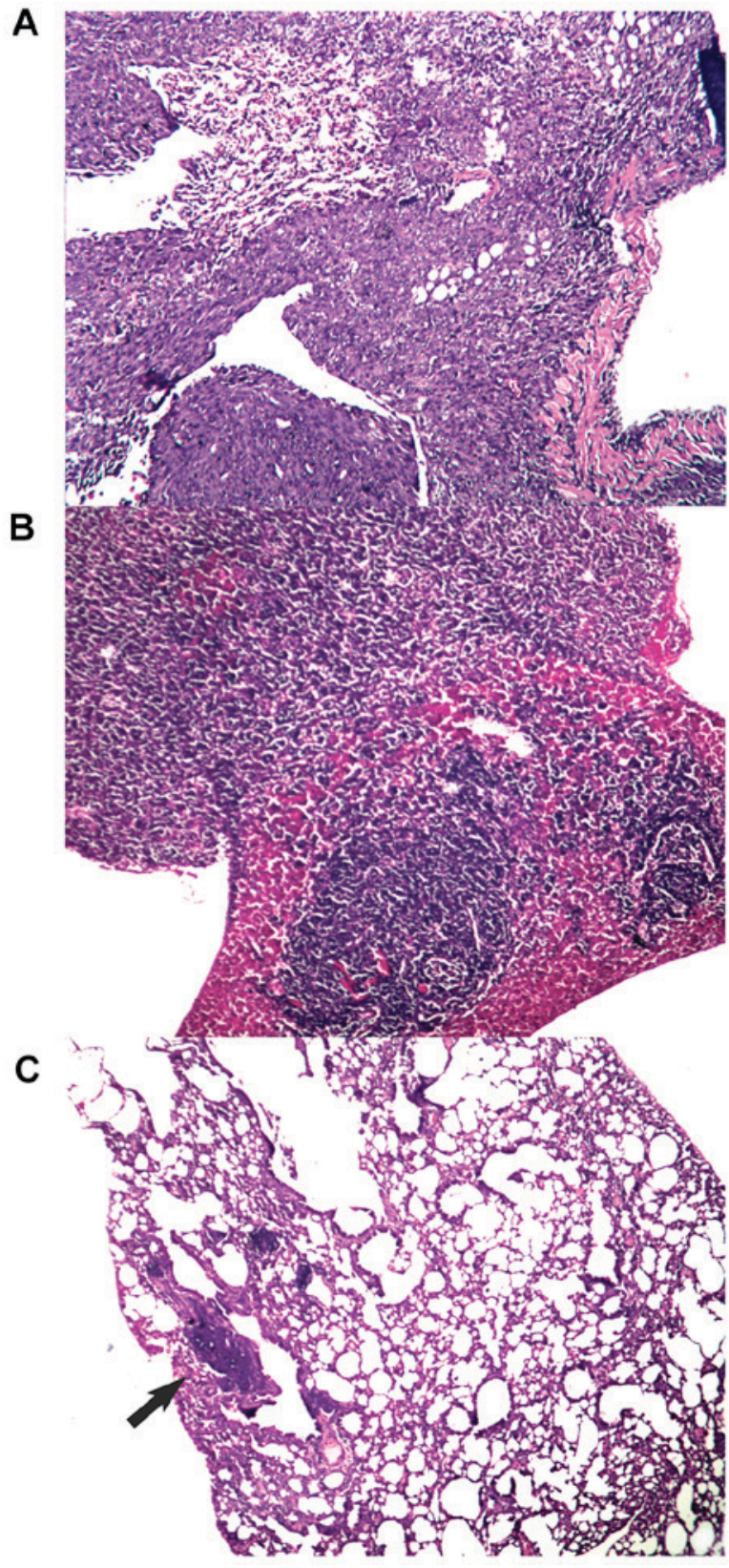

Figure 5. Histological analysis of lung samples from mice surviving the experiment (day 70). Histological slides from (A) control mice, (B) mice in the xeno rat experimental arm and $(C)$ mice in the xeno chicken experimental arm. Metastatic foci (A and B) fill the whole field of view or are (C) indicated by an arrow. Magnification, x100.

\section{Discussion}

The metastatic LLC model was introduced in the present study since the handling of oncological patients following primary tumour removal remains a challenge in modern oncology $(37,38)$. Lungs were primarily investigated for metastatic spread owing to the known characteristic of the LLC cell line, which spreads preferentially to lung tissue (30).

Survival analysis (Fig. 2) revealed that the xeno rat vaccine (rat brain adjuvanted with $B$. subtilis) produced results that were not statistically significant from the control $(\mathrm{P}=0.989)$. The mice in the xeno chicken vaccine group exhibited a $100 \%$ survival rate throughout the observation period. However, metastasis data (Fig. 5) revealed that $33 \%$ of slides produced from the lungs of mice that were treated with the xeno chicken vaccine had metastatic infiltrates in them. However, the size of these foci was considerably smaller compared with the control or xeno rat groups.

The long-surviving xeno chicken vaccination group was characterized by the highest proportion of $\mathrm{CD} 8 \mathrm{a}^{+}$in circulating blood from all investigated groups $(18.8 \%$ of T lymphocytes vs. $12,4 \%$ in Xeno Rat and $11,2 \%$ in control groups). This was a larger percentage compared with the value reported in a previous study (39), where a value of $16.6 \% \mathrm{CD} 8^{+}$ $\mathrm{T}$ lymphocytes was reported for an autologous lysate-based vaccine, which was considered to be clinically successful. The strong statistical correlation between the mean survival time and $\mathrm{CD} 8 \mathrm{a}^{+}$population size in the present study $(\mathrm{r}=0.985)$ indicates that cytotoxic T-lymphocytes may be a pivotal element in the vaccine-induced antitumour immune response, which is in agreement with data from the literature (40-44).

It is already recognized that individual xenogeneic vaccines do not work equally well against all types of cancer, as previously demonstrated for xeno chicken vaccine (22). Similarly, it was demonstrated in the present study that the xeno rat vaccine, which had a significant anti-metastatic effect following tumour resection on B16-bearing mice (25), does not succeed in the metastatic LLC setup. We hypothesize that, for the xeno rat vaccine, the cross-reactivity between the vaccine proteins and LLC antigens is inadequate, likely to be due to insufficient protein homology. In addition, distinct spectrum of TAAs in B16 melanoma and LCC lung cancer cells may be responsible for the xeno rat vaccine exhibiting 
activity in the former, but not the latter, tumour model, indicating that different xenovaccine formulations may be required for inducing or expanding immune responses against different tumours.

Moreover, in a previously investigated metastatic LLC model, where $B$. subtilis was used as an adjuvant for an autologous tumour lysate-based vaccine, B. subtilis failed to demonstrate satisfactory clinical benefit (39), and this underperformance was repeated in the present study. Various vaccines (preventive and therapeutic) are generally used with vaccine adjuvants that shape and potentiate the induced immune responses, thereby increasing the efficacy of vaccination $(45,46)$. The present study, however, demonstrates that a unadjuvanted xenogeneic vaccine (xeno chicken) can be successfully applied, and the xenogeneic component of the vaccine can serve as sufficient adjuvant on in its own right.

Therapeutic cancer vaccinations are the source of a great deal of interest and following various clinical successes and failures continues to be promising for oncological patients (47), particularly in combinational therapy settings (48). Despite the investigation of various therapeutic vaccines and application regimes in a plethora of clinical studies (49), only sipuleucel-T (Provenge; Dendreon Pharmaceuticals LLC, Seal Beach, CA, USA) has been approved to treat patients with metastatic, asymptomatic, castration-resistant prostate cancer (50). This indicates that therapeutic cancer vaccination protocols should be optimized and standardized in terms of selection of appropriate TAAs, adjuvants and regimens (route, dose and frequency of treatments) of vaccine administration, preferably in combination with other cancer treatment modalities. One of the critical factors determining the activity of vaccination is the immunogenicity of TAAs used for vaccination. It is believed that xenogeneic TAAs have increased immunogenicity due to the lack of intrinsic tolerogenicity, which is characteristic of self-protein-derived TAAs (8). Polyvalent vaccines based on lysates, with a rich pool of various antigens, are advantageous as the broad spectrum of targets provides cover for possible immunoediting (51) and tumour escape (52). The insight into the clinical outcomes of various xenovaccination therapies, highlighted in the present study, may benefit such trials and further enhance the therapeutic potential of xenogeneic therapeutic cancer vaccination.

Various preventive and therapeutic vaccines are generally used with vaccine adjuvants that shape and potentiate the induced immune responses, thereby increasing the efficacy of vaccination $(45,46)$. In a previously investigated metastatic LLC model, where B. subtilis was used as an adjuvant for an autologous tumour lysate-based vaccine, it failed to demonstrate satisfactory clinical benefits (39); an underperformance repeated in the present study. It is well established that the choice of an appropriate vaccine adjuvant is of critical importance, since inappropriate adjuvants may not only lack its desired activity, but also trigger tolerogenic immune response (53). Notably in the present study, it was revealed that the unadjuvanted xeno chicken vaccine was effective in terms of immune response and clinical outcome. The xenogeneic component of the vaccine may serve as a damage-associated molecular pattern that acts as an adjuvant. The identification of xenovaccine components that act as the source of immunogenic TAAs and as immune potentiators would allow for a reduction in the number of variables responsible for vaccine activity and the development of a more straightforward and standardised therapeutic product.

The results of the present study provide a further insight into the therapeutic potential of xenogeneic therapeutic cancer vaccinations, and may aid the direction of preclinical research and clinical trials in this field.

\section{References}

1. Mittal D, Gubin MM, Schreiber RD and Smyth MJ: New insights into cancer immunoediting and its three component phases-elimination, equilibrium and escape. Curr Opin Immunol 27: 16-25, 2014

2. Ferlay J, Soerjomataram I, Ervik M, Dikshit R, Eser S, Mathers C, Rebelo M, Parkin DM, Forman D and Bray F: GLOBOCAN 2012 v1.0, Cancer Incidence and Mortality Worldwide: IARC Cancer Base No. 11 [Internet]. Lyon, France, 2013.

3. Zitvogel L, Tesniere A and Kroemer G: Cancer despite immunosurveillance: Immunoselection and immunosubversion. Nat Rev Immunol 6: 715-727, 2006.

4. Galluzzi L, Vacchelli E, Bravo-San Pedro JM, et al: Classification of current anticancer immunotherapies. Oncotarget 5: 12472-12508, 2014.

5. Nestle FO, Alijagic S, Gilliet M, Sun Y, Grabbe S, Dummer R, Burg G and Schadendorf D: Vaccination of melanoma patients with peptide- or tumor lysate-pulsed dendritic cells. Nat Med 4: 328-332, 1998.

6. Strioga M,Schijns V,PowellDJ Jr,Pasukoniene V,DobrovolskieneN and Michalek J: Dendritic cells and their role in tumor immunosurveillance. Innate Immun 19: 98-111, 2013.

7. Strioga MM, Felzmann T, Powell DJ Jr, Ostapenko V, Dobrovolskiene NT, Matuskova M, Michalek J and Schijns VE: Therapeutic dendritic cell-based cancer vaccines: The state of the art. Crit Rev Immunol 33: 489-547, 2013.

8. Strioga MM, Darinskas A, Pasukoniene V, Mlynska A, Ostapenko V and Schijns V: Xenogeneic therapeutic cancer vaccines as breakers of immune tolerance for clinical application: To use or not to use? Vaccine 32: 4015-4024, 2014.

9. Weber LW, Bowne WB, Wolchok JD, Srinivasan R, Qin J, Moroi Y, Clynes R, Song P, Lewis JJ and Houghton AN: Tumor immunity and autoimmunity induced by immunization with homologous DNA. J Clin Invest 102: 1258-1264, 1998.

10. Overwijk WW, Lee DS, Surman DR, Irvine KR, Touloukian CE, Chan CC, Carroll MW, Moss B, Rosenberg SA and Restifo NP: Vaccination with a recombinant vaccinia virus encoding a 'self' antigen induces autoimmune vitiligo and tumor cell destruction in mice: requirement for CD4( $\left(^{+}\right)$T lymphocytes. Proc Natl Acad Sci USA 96: 2982-2987, 1999.

11. Wei YQ, Wang QR, Zhao X, Yang L, Tian L, Lu Y, Kang B, Lu CJ, Huang MJ, Lou YY, et al: Immunotherapy of tumors with xenogeneic endothelial cells as a vaccine. Nat Med 6: 1160-1166, 2000.

12. Steitz J, Brück J, Steinbrink K, Enk A, Knop J and Tüting T: Genetic immunization of mice with human tyrosinase-related protein 2: Implications for the immunotherapy of melanoma. Int J Cancer 86: 89-94, 2000.

13. Kornberg TB and Krasnow MA: The Drosophila genome sequence: Implications for biology and medicine. Science 287: 2218-2220, 2000.

14. Nilsson S, Helou K, Walentinsson A, Szpirer C, Nerman O and Ståhl F: Rat-mouse and rat-human comparative maps based on gene homology and high-resolution zoo-FISH. Genomics 74: 287-298, 2001.

15. Overwijk WW, Tsung A, Irvine KR, Parkhurst MR, Goletz TJ, Tsung K, Carroll MW, Liu C, Moss B, Rosenberg SA and Restifo NP: gp100/pmel 17 is a murine tumor rejection antigen: Induction of 'self'-reactive, tumoricidal T cells using high-affinity, altered peptide ligand. J Exp Med 188: 277-286, 1998.

16. Soong RS, Trieu J, Lee SY, He L, Tsai YC, Wu TC and Hung CF: Xenogeneic human p53 DNA vaccination by electroporation breaks immune tolerance to control murine tumors expressing mouse p53. PLoS One 8: e56912, 2013.

17. Fong L, Brockstedt D, Benike C, Breen JK, Strang G, Ruegg CL and Engleman EG: Dendritic cell-based xenoantigen vaccination for prostate cancer immunotherapy. J Immunol 167: 7150-7156, 2001. 
18. Wepsic HT: Overview of oncofetal antigens in cancer. Ann Clin Lab Sci 13: 261-266, 1983.

19. Lim SH, Zhang Y and Zhang J: Cancer-testis antigens: The current status on antigen regulation and potential clinical use. Am J Blood Res 2: 29-35, 2012.

20. Malati T: Tumour markers: An overview. Indian J Clin Biochem 22: 17-31, 2007.

21. Ohue Y, Wada H, Oka M and Nakayama E: Antibody response to cancer/testis (CT) antigens: A prognostic marker in cancer patients. Oncoimmunology 3: e970032, 2014

22. Symchych TV, Fedosova NI, Karaman OM, Yevstratieva LM, Lisovenko HS, Voyejkova IM and Potebnia HP: The anticancer efficiency of the xenogeneic vaccine and the indication for its use. Exp Oncol 36: 79-84, 2014.

23. Seledtsova GV, Shishkov AA, Kaschenko EA, Goncharov AG, Gazatova ND and Seledtsov VI: Xenogeneic cell-based vaccine therapy for stage III melanoma: Safety, immune-mediated responses and survival benefits. Eur J Dermatol 26: 138-143, 2016.

24. Seledtsova GV, Shishkov AA, Kaschenko EA and Seledtsov VI: Xenogeneic cell-based vaccine therapy for colorectal cancer: Safety, association of clinical effects with vaccine-induced immune responses. Biomed Pharmacother 83: 1247-1252, 2016.

25. Voeykova IM, Fedosova NI, Karaman OM, Yudina OY, Didenko GV, Lisovenko GS, Evstratieva LM and Potebnya GP Use of xenogeneic vaccine modified with embryonal nervous tissue antigens in the treatment of B16-melanoma-bearing mice. Exp Oncol 36: 24-28, 2014

26. Directive 2010/63/EU of the European Parliament and of the Council of 22 September 2010 on the protection of animals used for scientific purposes, pp33-79, 2010.

27. Potebnya GP VI, Yudina OYu, Fedosova NI, Karaman OM, Didenko GV, Yevstratyeva LM, Lisovenko GS and Chekhun VF: The way to generate cancer vaccine. UKRPATENT (ed.), Ukraine, 2013 .

28. Isokawa K, Rezaee M, Wunsch A, Markwald RR and Krug EL: Identification of transferrin as one of multiple EDTA-extractable extracellular proteins involved in early chick heart morphogenesis. J Cell Biochem 54: 207-218, 1994.

29. Symchych TV, Fedosova NI, Karaman OM, Yevstratieva LM, Lisovenko HS, Voyeykova IM and Potebnia HP: Anticancer effectiveness of vaccination based on xenogeneic embryo proteins applied in different schedules. Exp Oncol 37: 197-202, 2015.

30. Niu PG, Zhang YX, Shi DH, Liu Y, Chen YY and Deng J: Cardamonin inhibits metastasis of lewis lung carcinoma cells by decreasing mTOR activity. PLoS One 10: e0127778, 2015.

31. Schneider CA, Rasband WS and Eliceiri KW: NIH Image to ImageJ: 25 years of image analysis. Nat Methods 9: 671-675, 2012 .

32. Bland JM and Altman DG: The logrank test. BMJ 328: 1073, 2004.

33. Judge GD, William EG, Hill RC and Lee TC: The theory and practise of econometrics. John Wiley \& Sons, New York, pp739, 1980.

34. Box GEP and Cox DR: An analysis of transformations. J R Stat Soc 26: 211-252, 1964.

35. Gosset WS: The probable error of a mean. Biometrica 6: 1-25, 1908.

36. Mann HB and Whitney DR: On a test of whether one of two random variables is stochastically larger than the other. Ann Math Stat 18: 50-60, 1947.

37. Schirrmacher V, Fournier P and Schlag P: Autologous tumor cell vaccines for post-operative active-specific immunotherapy of colorectal carcinoma: Long-term patient survival and mechanism of function. Expert Rev Vaccines 13: 117-130, 2014.
38. Laufer I, Iorgulescu JB, Chapman T, Lis E, Shi W, Zhang Z, Cox BW, Yamada Y and Bilsky MH: Local disease control for spinal metastases following 'separation surgery' and adjuvant hypofractionated or high-dose single-fraction stereotactic radiosurgery: Outcome analysis in 186 patients. J Neurosurg Spine 18: 207-214, 2013.

39. Kraśko JA, Žilionytė K, Darinskas A, Strioga M, Rjabceva S, Zalutsky I, Derevyanko M, Kulchitsky V, Lubitz W, Kudela P, et al: Bacterial ghosts as adjuvants in syngeneic tumour cell lysate-based anticancer vaccination in a murine lung carcinoma model. Oncol Rep 37: 171-178, 2017.

40. Foged C, Hansen J and Agger EM: License to kill: Formulation requirements for optimal priming of CD8(+) CTL responses with particulate vaccine delivery systems. Eur J Pharm Sci 45: 482-491, 2012

41. Sandoval F, Terme M, Nizard M, Badoual C, Bureau MF, Freyburger L, Clement O, Marcheteau E, Gey A, Fraisse G, et al: Mucosal imprinting of vaccine-induced CD8(+)T cells is crucial to inhibit the growth of mucosal tumors. Sci Transl Med 5: 172ra120, 2013.

42. Chen LJ, Zheng X, Shen YP, Zhu YB, Li Q, Chen J, Xia R, Zhou SM, Wu CP, Zhang XG, et al: Higher numbers of T-bet(+) intratumoral lymphoid cells correlate with better survival in gastric cancer. Cancer Immunol Immunother 62: 553-561, 2013.

43. Noguchi A, Kaneko T, Naitoh K, Saito M, Iwai K, Maekawa R, Kamigaki T and Goto S: Impaired and imbalanced cellular immunological status assessed in advanced cancer patients and restoration of the $\mathrm{T}$ cell immune status by adoptive T-cell immunotherapy. Int Immunopharmacol 18: 90-97, 2014.

44. Thiery J and Lieberman J: Perforin: A key pore-forming protein for immune control of viruses and cancer. Subcell Biochem 80: 197-220, 2014

45. Pérez O, Batista-Duharte A, González E, Zayas C, Balboa J, Cuello M, Cabrera O, Lastre M and Schijns VE: Human prophylactic vaccine adjuvants and their determinant role in new vaccine formulations. Braz J Med Biol Res 45: 681-692, 2012.

46. Schijns V, Tartour E, Michalek J, Stathopoulos A, Dobrovolskiene NT and Strioga MM: Immune adjuvants as critical guides directing immunity triggered by therapeutic cancer vaccines. Cytotherapy 16: 427-439, 2014.

47. Guo C, Manjili MH, Subjeck JR, Sarkar D, Fisher PB and Wang XY: Therapeutic cancer vaccines: Past, present, and future. Adv Cancer Res 119: 421-475, 2013.

48. Andersen MH, Junker N, Ellebaek E, Svane IM and Thor Straten P: Therapeutic cancer vaccines in combination with conventional therapy. J Biomed Biotechnol 2010: 237623, 2010.

49. Melero I, Gaudernack G, Gerritsen W, Huber C, Parmiani G, Scholl S, Thatcher N, Wagstaff J, Zielinski C, Faulkner I and Mellstedt H: Therapeutic vaccines for cancer: An overview of clinical trials. Nat Rev Clin Oncol 11: 509-524, 2014.

50. Cheever MA and Higano CS: PROVENGE (Sipuleucel-T) in prostate cancer: The first FDA-approved therapeutic cancer vaccine. Clin Cancer Res 17: 3520-3526, 2011.

51. Vesely MD and Schreiber RD: Cancer immunoediting: Antigens, mechanisms, and implications to cancer immunotherapy. Ann $\mathrm{N}$ Y Acad Sci 1284: 1-5, 2013

52. Dunn GP, Old LJ and Schreiber RD: The three Es of cancer immunoediting. Annu Rev Immunol 22: 329-360, 2004.

53. Dang Y, Wagner WM, Gad E, Rastetter L, Berger CM, Holt GE and Disis ML: Dendritic cell-activating vaccine adjuvants differ in the ability to elicit antitumor immunity due to an adjuvant-specific induction of immunosuppressive cells. Clin Cancer Res 18: 3122-3131, 2012. 